\title{
Prediction of Microstructure Evolution in Hot Backward Extrusion of Ti-6Al-4V Alloy
}

\author{
Jong-Taek Yeom, ${ }^{1}$ Jeoung Han Kim, ${ }^{1}$ Jae-Keun Hong, ${ }^{1}$ \\ Nho-Kwang Park, ${ }^{1}$ and Chong Soo Lee ${ }^{2}$ \\ ${ }^{1}$ Special Alloys Group, Korea Institute of Materials Science, 531 Changwondaero, Changwon 641-831, Republic of Korea \\ ${ }^{2}$ Department of Materials Science and Engineering, POSTECH, San 31, Hyojadong, Namgu, \\ Pohang 790-784, Republic of Korea
}

Correspondence should be addressed to Jong-Taek Yeom, yjt96@kims.re.kr

Received 28 September 2011; Accepted 21 October 2011

Academic Editor: Enrico Evangelista

Copyright (C) 2012 Jong-Taek Yeom et al. This is an open access article distributed under the Creative Commons Attribution License, which permits unrestricted use, distribution, and reproduction in any medium, provided the original work is properly cited.

\begin{abstract}
Microstructure evolution of Ti-6Al-4V alloy during hot backward extrusion process was simulated with the combined approaches of finite element method (FEM) and microstructure prediction model. From experimental analysis, it can be found that the change of microstructure during hot forming process of titanium alloy has a close relation to $\alpha / \beta$ phase transformation and grain growth behaviour. A microstructure prediction model was established by considering the change of volume fractions and grain size of both phases varying with process variables and then implemented into the user-defined subroutine of FEM analysis. In order to demonstrate the reliability of the model, the volume fraction and grain size of primary $\alpha$ phase during the hot backward extrusion process of Ti-6Al-4V alloy were simulated. The simulation results were compared with the experimental ones.
\end{abstract}

\section{Introduction}

Computer simulation is an important and effective tool for the optimized forming processes and to reduce error which may be caused by trial and error method. Finite element (FE) analysis is widely used for the simulation of shape and microstructure changes in hot forming [1-3]. With the improvement in understanding of the relationship between microstructures and mechanical properties of structural components, the prediction of shape and microstructure changes has become a hot issue in the high-temperature forming.

The high-temperature forming processes for manufacturing titanium alloy products are normally conducted on the equiaxed structure in two-phase $(\alpha+\beta)$ field [4]. The microstructure change is mainly indicated as the change of volume fraction and grain size of $\alpha$ and $\beta$ phases. It may be due to phase transformation and grain growth during the high temperature forming. In the past, most of microstructure simulations have focused on the prediction of the single-phase alloys using the recrystallization and grain growth models [5]. However, only a limited work $[6,7]$ has been carried out on the simulation for microstructure evolution of Ti-6Al-4V alloy during hot forming processes. Therefore, the aim of this research is to establish the methodology for prediction of the microstructure evolution of Ti-6Al-4V components during high-temperature forming processes, and to develop a useful design tool for obtaining the optimum process condition in the high-temperature forming processes using finite element method (FEM) simulation.

\section{Experimental Procedures}

The material used in this work was a Ti-6Al-4V alloy billet annealed at $704^{\circ} \mathrm{C}$ for $2 \mathrm{~h}$ with a diameter of $100 \mathrm{~mm}$. The chemical composition of the alloy is $6.32 \mathrm{Al}, 4.18 \mathrm{~V}, 0.21 \mathrm{Fe}$, $0.014 \mathrm{C}, 0.18 \mathrm{O}, 0.008 \mathrm{~N}, 0.001 \mathrm{Y}$, and balance $\mathrm{Ti}$ (in wt $\%$ ). Initial microstructure of Ti-6Al-4V alloy was an equiaxed structure with the primary $\alpha$ grain size of about $16 \mu \mathrm{m}$ as shown in Figure 1.

In order to investigate flow behavior and microstructure evolution of Ti-6 Al- $4 \mathrm{~V}$ alloy in the $\alpha-\beta$ phase field, 


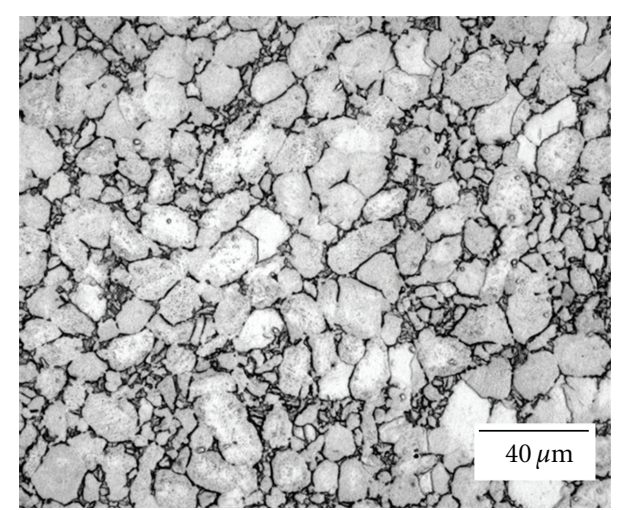

Figure 1: Typical microstructure of the annealed Ti-6Al-4V alloy billet.

compression and heat treatment tests were carried out. Compression tests were performed in the temperature ranges between $850^{\circ} \mathrm{C}$ and $1000^{\circ} \mathrm{C}$ with $25^{\circ} \mathrm{C}$ intervals using the strain rate ranging from $10^{-3}$ to $10 \mathrm{~s}^{-1}$. Heat treatment tests were carried out with the holding time of $30 \mathrm{~min}$ between 900 and $1015^{\circ} \mathrm{C}$. To observe the actual microstructure at the test temperature, after the holding time of $30 \mathrm{~min}$, the heat-treated samples were water-quenched. To analyze the microstructure evolution during cooling, the samples were heat-treated at the temperature of $900,925,950$, and $975^{\circ} \mathrm{C}$ for $30 \mathrm{~min}$. Following the heat treatment, the samples were cooled down using different cooling rates.

In order to verify the reliability of the established microstructure prediction model, Ti-6Al-4V alloy tube was manufactured by hot backward extrusion process using a 150 ton hydraulic press. Backward extrusion process for evaluating the reliability of the model was selected to predict microstructure variation during actual hot working considering friction, interface heat transfer, and process variables. The design of the dies (punch and lower die) and preform is represented in Figure 2. Oil-based graphite lubricant was spread into the punch and lower dies to reduce die friction. The preform of Ti-6Al-4V alloy was glass-coated and heated to an extrusion temperature of $970^{\circ} \mathrm{C}$. The punch and die temperatures were selected at $500^{\circ} \mathrm{C}$ and $600^{\circ} \mathrm{C}$, respectively. After the backward extrusion, the Ti-6Al-4V tube was water-quenched.

\section{Results and Discussion}

Figure 3 shows the change of microstructures with increasing the heating temperature obtained from isothermal heat treatment tests of Ti-6Al-4V alloy. It can be found that the volume fraction and grain size of $\alpha$ phase decrease with increasing the heating temperature, and especially the grain size of $\alpha$ phase markedly decreases from more than $950^{\circ} \mathrm{C}$. The $\beta$ phase grains remain constant up to $950^{\circ} \mathrm{C}$ and dramatically grow at $975^{\circ} \mathrm{C}$. This is in agreement with the observations by Semiatin et al. [8].

Figure 4 shows the change of microstructure with increasing hold time obtained from isothermal heat treatment tests of Ti- $6 \mathrm{Al}-4 \mathrm{~V}$ alloy. It is noted that the $\alpha$ grain

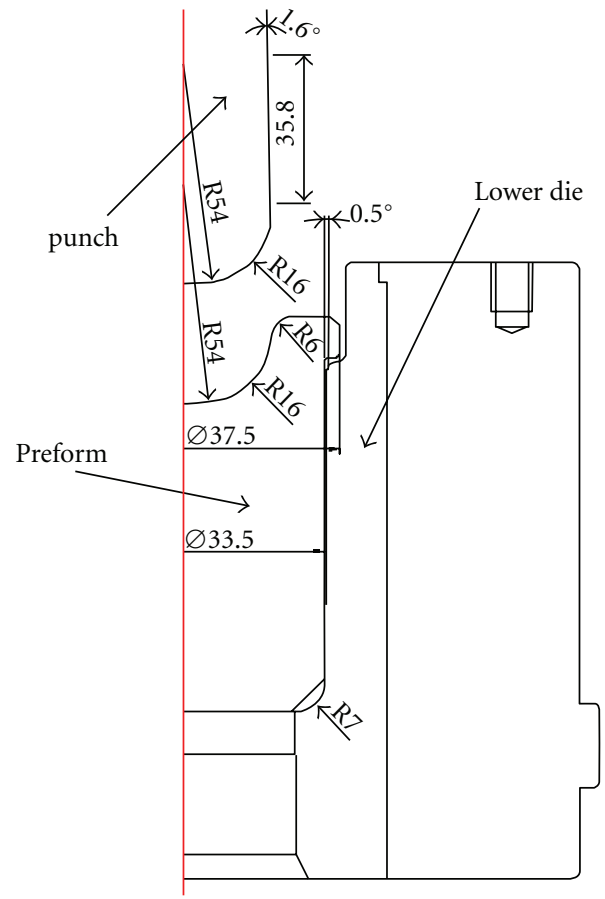

FIGURE 2: Design of the punch, lower die, and preform used in hot backward extrusion.

size does not change significantly with holding time whereas $\beta$ grain size increases considerably. This is due to the high diffusivity in $\beta$ phase.

In general, mechanical properties of Ti-6Al-4V alloy products forged at $\alpha-\beta$ region were directly affected by the volume fraction and grain size of equiaxed primary $\alpha$ phase. The microstructure prediction model reflecting microstructure evolution during heating and high temperature deformation is established in this work. To predict the volume fraction and grain size of primary $\alpha$ phase, the geometrical model for grain size change of $\alpha$ phase developed in previous work $[2,9,10]$ was used. Assuming that the total numbers of $\alpha$ grains and $\beta$ grain size are constant, the grain size of $\alpha$ phase $(d)$ can be calculated by following equation:

$$
d=d_{0}\left(\frac{f_{\alpha}}{f_{\alpha 0}}\right)^{1 / 3} \quad(\mu \mathrm{m}),
$$

where $d_{0}$ and $f_{\alpha 0}$ are the initial grain size and volume fraction of primary $\alpha$ phase, respectively, and $f_{\alpha}$ is the present volume fraction of primary $\alpha$ phase. Meanwhile, the volume fractions of each phase during heating and soaking can be expressed as a function of initial volume fractions of each phase and temperature

$$
\begin{gathered}
f_{\alpha}=f_{\alpha, R T}+\left(1-\exp \left(-k \cdot\left\langle T_{\beta}-T\right\rangle\right)\right) \\
f_{\beta}=1-f_{\alpha},
\end{gathered}
$$

where $f_{\beta_{0}}$ and $f_{\beta}$ are initial volume fraction and present volume fraction of $\beta$ phase, respectively. $f_{\alpha, R T}$ is the volume fraction of primary $\alpha$ phase at room temperature. The magnitude of $\left\langle T_{\beta}-T\right\rangle$ is zero when $T_{\beta}-T \leq 0$, and it is 


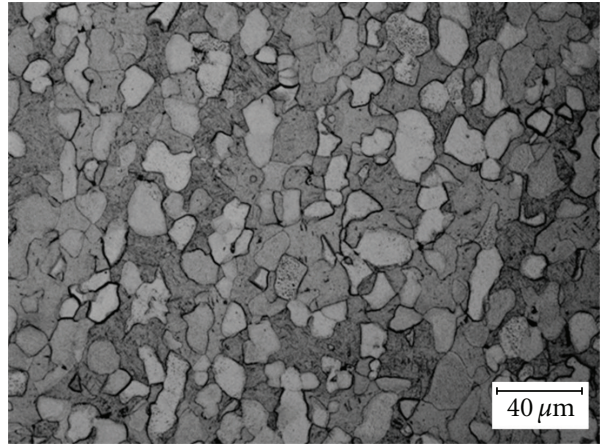

(a)

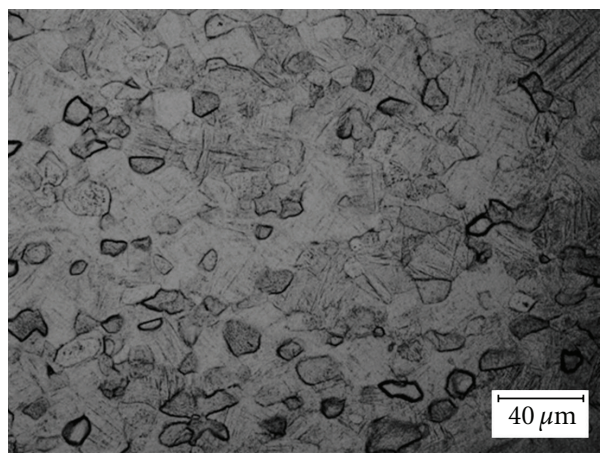

(c)

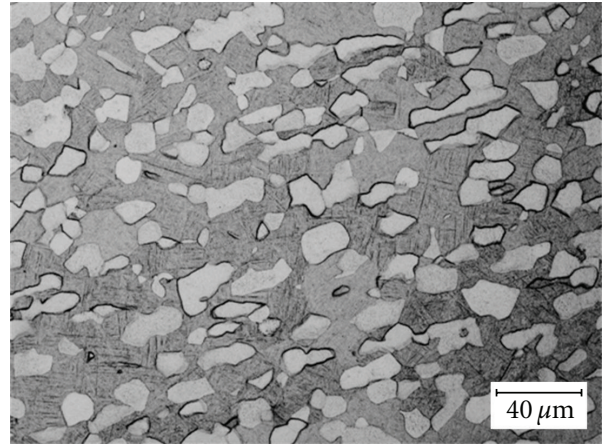

(b)

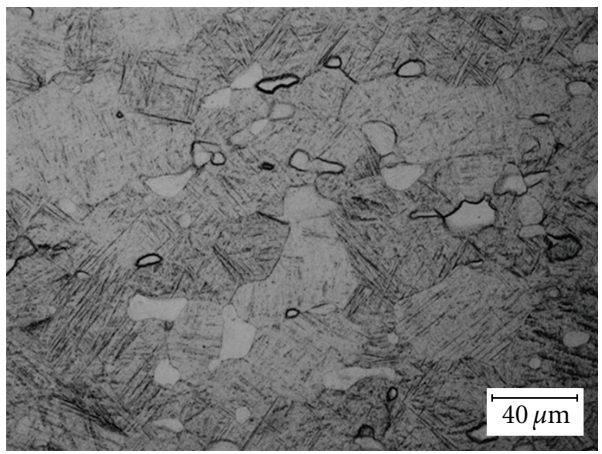

(d)

Figure 3: Microstructures of Ti-6Al-4V alloy samples water quenched after a 30 min heat treatment at (a) $900^{\circ} \mathrm{C},(\mathrm{b}) 925^{\circ} \mathrm{C},(\mathrm{c}) 950^{\circ} \mathrm{C}$, and (d) $975^{\circ} \mathrm{C}$.

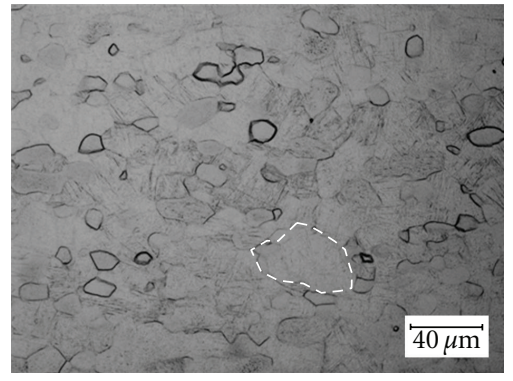

(a)

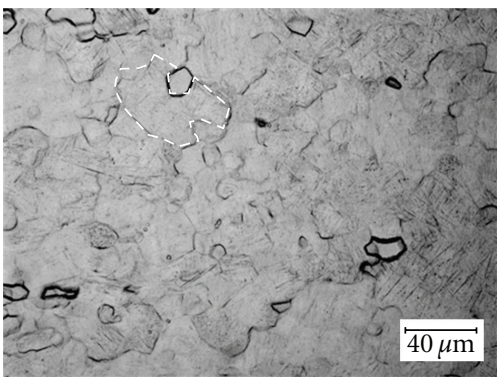

(b)

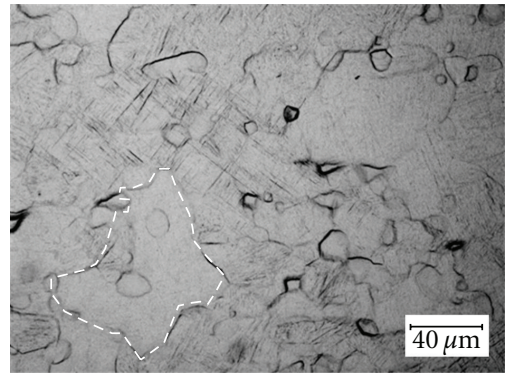

(c)

Figure 4: Microstructures of Ti-6Al-4V alloy samples water quenched after isothermal heat treatment at $950^{\circ} \mathrm{C}$ for (a) $10 \mathrm{~min}$, (b) $1 \mathrm{~h}$, and (c) $10 \mathrm{~h}$. White dotted lines indicate $\beta$ grains.

$T_{\beta}-T$ in other case. Through the isothermal heat treatment tests, the parameters $f_{\alpha, R T}$ and $k$ in Ti-6Al-4V alloy with an equiaxed structure were determined by 0.942 and $8.17 \times 10^{-3}$, respectively.

In $\alpha-\beta \mathrm{Ti}$ alloys, phase transformation $(\beta \rightarrow \alpha)$ also occurs during cooling and forming. In order to express the volume fraction change of $\alpha$ phase during cooling and forming, the Avrami-type equation was applied

$$
\begin{gathered}
f_{\alpha, c}=f_{\alpha, h}+\left(f_{\alpha, R T}-f_{\alpha, h}\right) \cdot\left(1-\exp \left(-f(T) \cdot t^{n}\right)\right) \\
f(T)=A \cdot\left(\frac{T_{\text {heat }}-T}{T_{\text {heat }}-T_{e}}\right)^{n^{\prime}},
\end{gathered}
$$

where $f_{\alpha, h}$ are the volume fraction of $\alpha$ phase after heating and soaking. $T_{\text {heat }}$ is heating or soaking temperature. $T_{e}$ represents the finishing temperature of phase transformation and this value is assumed to be $298 \mathrm{~K}$. The values of $n, n^{\prime}$, and A were 1, 6.67, and 0.0023, respectively.

A commercial FEM code, DEFORM 2D, was used to simulate the effect of process variables in hot backward extrusion process of Ti-6Al-4V alloy on the distribution of the internal state variables such as strain, strain rate, and temperature. The flow stress data obtained from compression tests were corrected for temperature increment calculated by the following equation:

$$
\Delta T=\frac{0.9 \int_{0}^{\varepsilon} p \sigma d \varepsilon}{\rho C},
$$



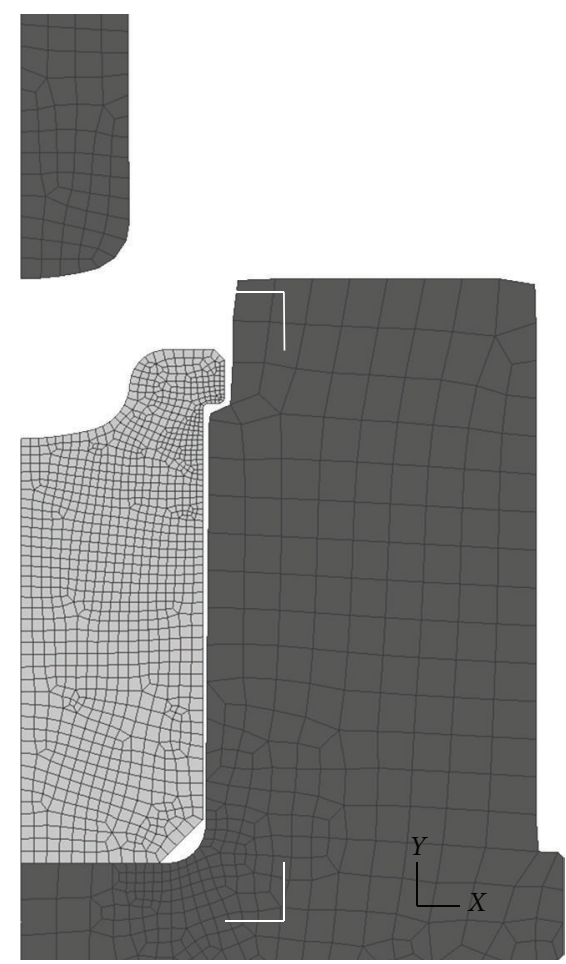

FIGURE 5: FEM modeling for hot backward extrusion process of Ti-6Al-4V alloy.

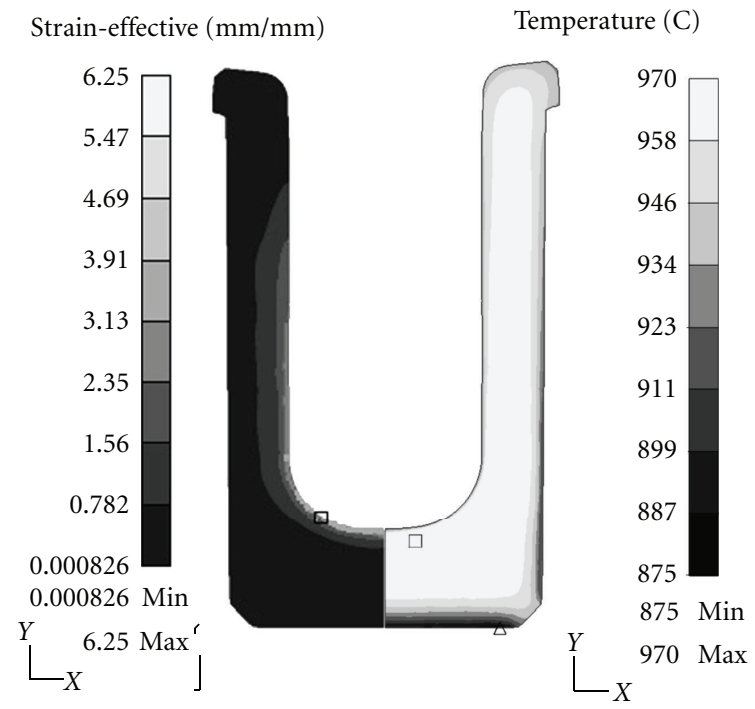

FIGURE 6: Temperature and effective strain contours for hot backward extrusion simulation of Ti-6Al-4V alloy.

where $\varepsilon_{p}$ is plastic strain, $\rho$ is density of material, and $C$ is specific heat. Corrected flow stress data were directly used to simulate material behavior of Ti-6Al-4V alloy during hot backward extrusion.

Generally, the friction between dies and workpiece is expressed by the friction law of constant factor. Also, interface heat transfer between dies and workpiece greatly affects the temperature change of the workpiece during hot forming process. Based on the results of previous work [11], the friction coefficient and interface heat transfer coefficient were determined at 0.3 and $5.0 \mathrm{~kW} / \mathrm{m}^{2 \circ} \mathrm{C}$, respectively. The element used in the simulation is brick elements, and automatic remeshing system was adopted during simulation. Figure 5 shows the 2D modeling for dies and initial preform shapes.

Figure 6 shows simulation results of strain and temperature distributions of hot backward extrusion process of Ti-6Al-4V alloy tube. The simulation results indicate that the highest strain region in the workpiece is found at inner wall, which is in contact with the punch during 

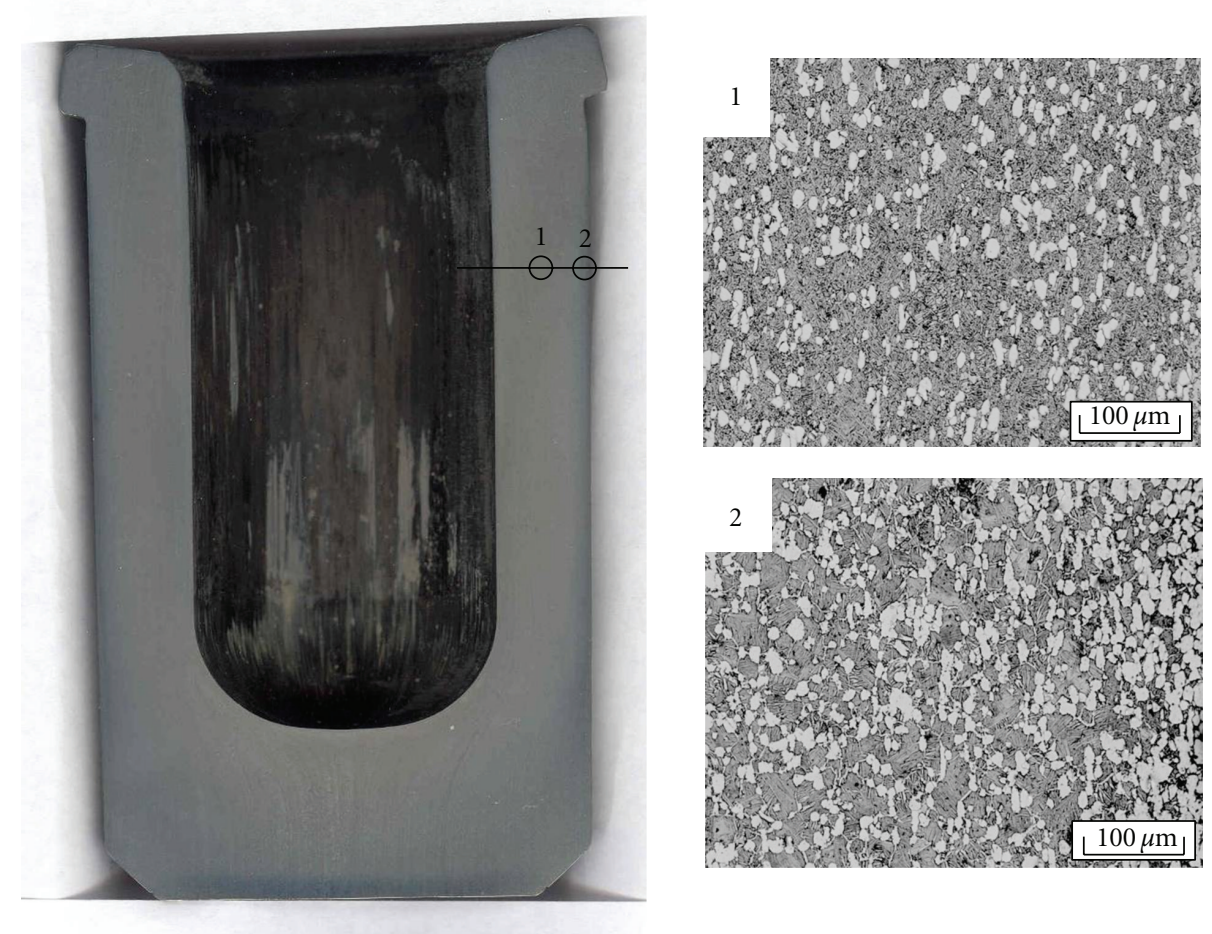

Figure 7: Microstructures observed at different locations for backward extruded Ti-6Al-4V alloy tube.

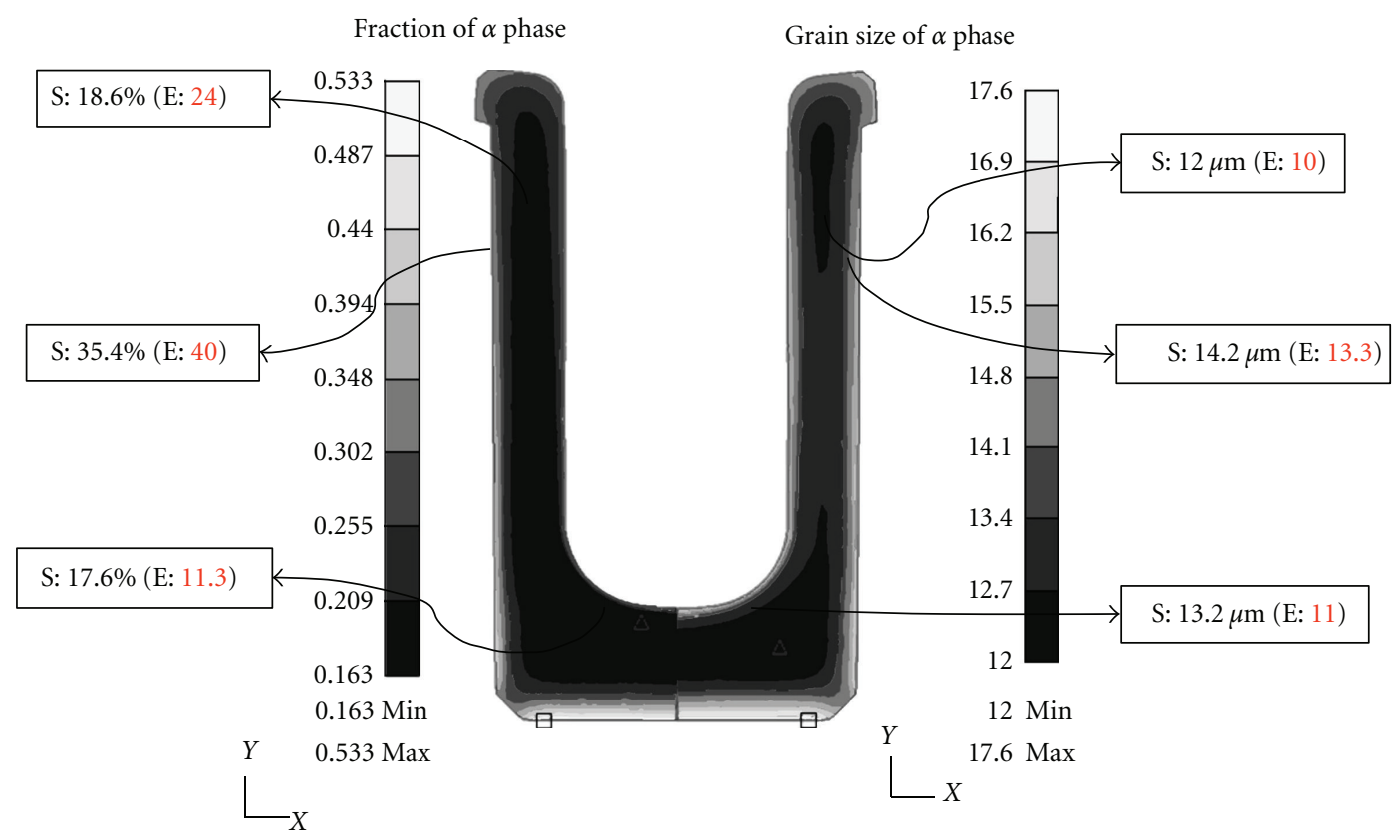

FIGURE 8: Contours of volume fraction and grain size of primary $\alpha$ phase for hot backward extrusion simulation of Ti-6Al-4V alloy. The symbols " $S$ " and " $E$ " in the bracket denote simulation and experimental results, respectively.

the forming process, and the temperature level at die contact area (or surface area) is lower than that at middle area due to heat transfer between dies and workpiece. Also, the lowest temperature region in the workpiece is found at the bottom, which is in constant contact with the lower die throughout the forming process from the moment the preform is transferred to the die.

Figure 7 shows the Ti-6Al-4V alloy tube manufactured by hot backward extrusion process and the microstructures observed at the cross-section of the tube. It can be found 
that extruded Ti-6Al-4V alloy tube is formed without the surface defects. Microstructures observed at most locations indicate a bimodal structure composed of equiaxed $\alpha$ and transformed beta phases. In the microstructural observation from surface to middle positions, it can be seen that the volume fraction of $\alpha$ phase at middle position is smaller than that of $\alpha$ phase at surface.

These microstructure changes during the extrusion process were closely related to the plastic strain and temperature varying at different positions. In this work, in order to predict the $\alpha$ grain size and the $\alpha / \beta$ phases volume fraction change, the decoupled approach between the microstructure model and FE analysis was applied. The model for predicting the volume fraction change and grain size of $\alpha$ phase was implemented into a post-user-defined subroutine of a commercial FE-code, DEFORM-2D.

Figure 8 shows the comparison between experimental data and simulation results. The experimental data measured from extruded tube were overlapped aside from simulation results. the values in the brackets especially indicate the experimental data. It was found that reasonable accuracy was obtained at most of region and the average deviation was below $15 \%$. Only at a certain part of inner wall, $36 \%$ of error was noticed which is due to the contact of the inner wall with the punch occurring in the given microstructures. It is clearly demonstrated that simulation results of volume fraction and grain size of $\alpha$ phase at most locations for the extruded Ti-6Al-4V tube were relatively close to measured values. Consequently, it is suggested that the microstructure simulation module is very useful for hot forming process design of Ti-6Al-4V alloy.

\section{Conclusions}

In this work, the microstructure evolution of Ti-6Al-4V tube during hot extrusion process was predicted by decoupled approach of $\mathrm{FE}$ analysis and microstructure prediction model. In order to evaluate the volume fraction and grain size of $\alpha$ phase during the hot backward extrusion process, the microstructure prediction model of Ti- $6 \mathrm{Al}-4 \mathrm{~V}$ alloy was suggested and implemented into the post-user subroutine of FE code. The comparison of the microstructure simulation module with the actual microstructures of the backward extruded Ti-6Al-4V alloy tube has successfully validated the reliability of the present module in the prediction of the volume fraction and grain size of $\alpha$ phase.

\section{Acknowledgments}

This research was partly supported by a grant through the research program funded by the Agency for Defense Development, Korea, and also partly supported by a grant through the research program (UCN248-2865.C) funded by the Ministry of Knowledge Economy, Korea.

\section{References}

[1] X. Duan and T. Sheppard, "Simulation and control of microstructure evolution during hot extrusion of hard aluminium alloys," Materials Science and Engineering A, vol. 351, no. 1-2, pp. 282-292, 2003.

[2] J. T. Yeom, J. H. Kim, N. K. Park, S. S. Choi, and C. S. Lee, "Ring-rolling design for a large-scale ring product of Ti-6Al4V alloy," Journal of Materials Processing Technology, vol. 187188, pp. 747-751, 2007.

[3] J. H. Kim, N. S. Reddy, J. T. Yeom, J. K. Hong, C. S. Lee, and N. K. Park, "Microstructure prediction of two-phase titanium alloy during hot forging using artificial neural networks and fe simulation," Metals and Materials International, vol. 15, no. 3, pp. 427-437, 2009.

[4] S. L. Semiatin, V. Seetharaman, and I. Weiss, "The thermomechanical processing of alpha/beta titanium alloys," JOM, vol. 49, no. 6, pp. 33-68, 1997.

[5] C. M. Sellars and J. A. Whiteman, "Recrystallization and grain growth in hot rolling," Metal Science, vol. 13, no. 3-4, pp. 187194, 1978.

[6] Z. M. Hu, J. W. Brooks, and T. A. Dean, "Experimental and theoretical analysis of deformation and microstructural evolution in the hot-die forging of titanium alloy aerofoil sections," Journal of Materials Processing Technology, vol. 88, no. 1, pp. 251-265, 1999.

[7] S. L. Semiatin, J. C. Soper, and I. M. Sukonnik, "Short-time beta grain growth kinetics for a conventional titanium alloy," Acta Materialia, vol. 44, no. 5, pp. 1979-1986, 1996.

[8] S. L. Semiatin, F. Montheillet, G. Shen, and J. J. Jonas, "Self-consistent modeling of the flow behavior of wrought alpha/beta titanium alloys under isothermal and nonisothermal hot-working conditions," Metallurgical and Materials Transactions A, vol. 33, no. 8, pp. 2719-2727, 2002.

[9] J. D. Miller and S. L. Semiatin, "Effect of the size distribution of alpha particles on microstructure evolution during heat treatment of an alpha/beta titanium alloy," Metallurgical and Materials Transactions A, vol. 36, no. 1, pp. 259-262, 2005.

[10] Y. H. Lee, C. S. Lee, T. J. Shin, S. M. Hwang, and S. M. Shim, "High Temperature Forming of Ti-6Al-4V Alloy Considering Microstructural Evolution," Key Engineering Materials, vol. 274-276, pp. 117-122, 2004.

[11] I. T. Yeom, N. K. Park, Y. H. Lee et al., "An improved process design for the hot backward extrusion of Ti-6Al-4V tubes using a finite element method and continuum instability criterion," Proceedings of the Institution of Mechanical Engineers, Part B, vol. 221, no. 2, pp. 255-265, 2007. 

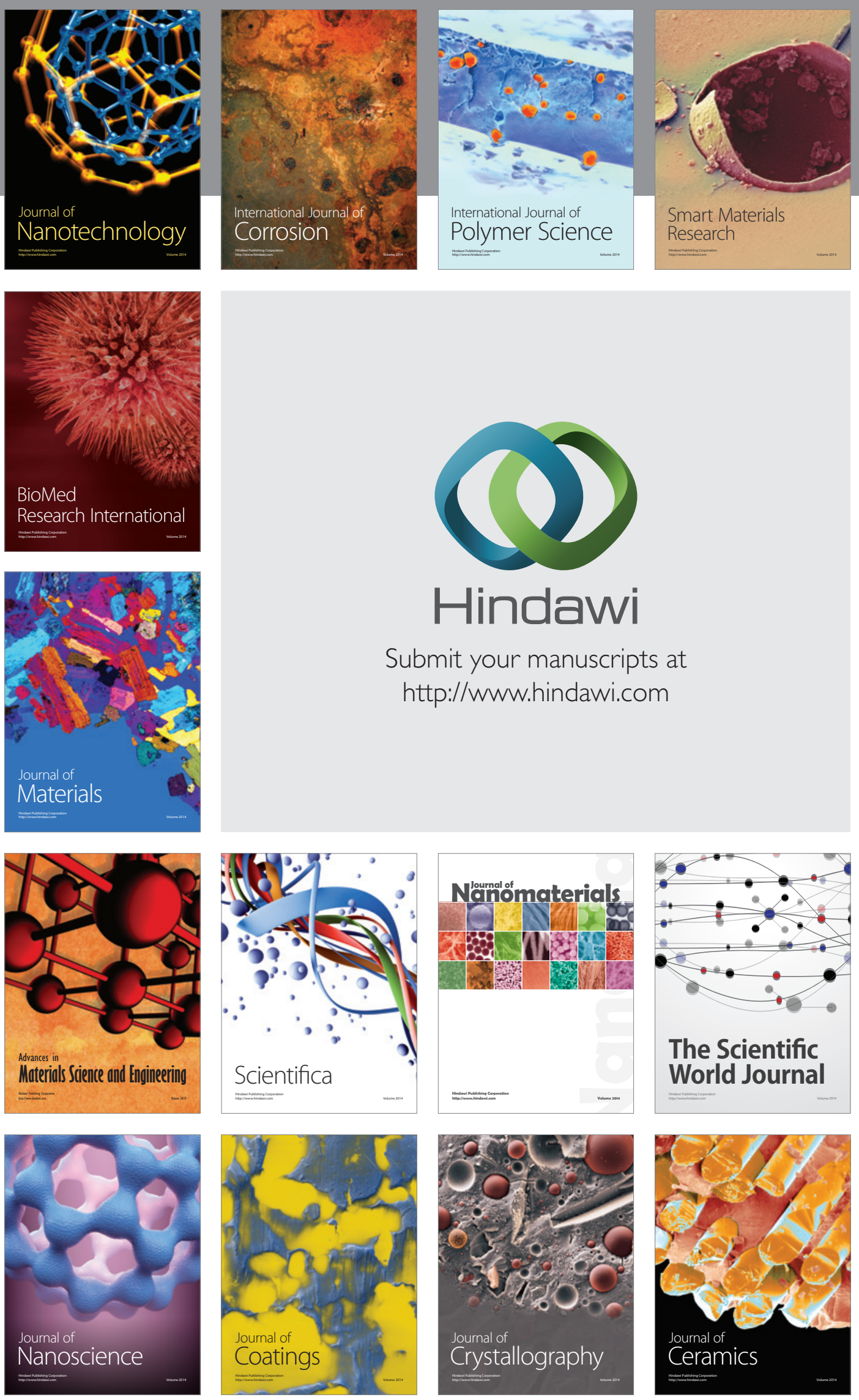

The Scientific World Journal

Submit your manuscripts at

http://www.hindawi.com

\section{World Journal}

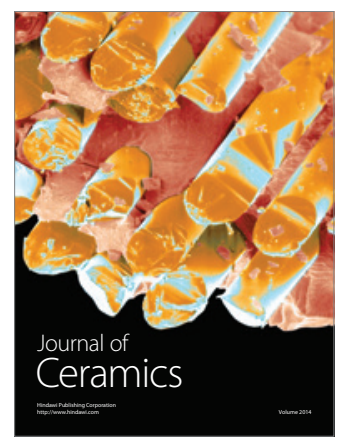

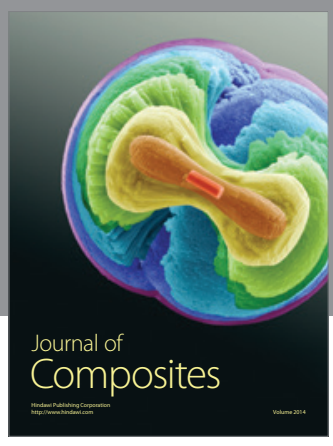
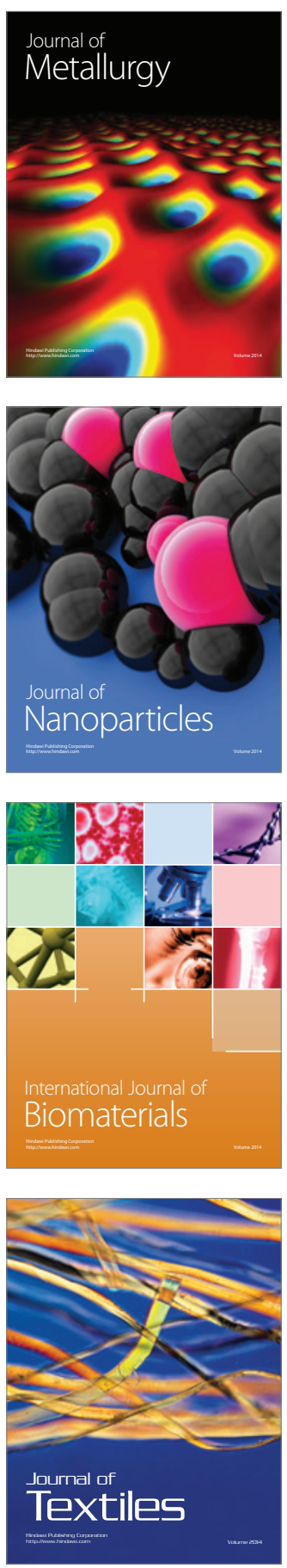